\title{
Atração e distração visual nos cavaletes eleitorais dos candidatos
}

\author{
Sérgio Roberto Trein
}

\section{Introdução}

$\mathrm{E}$ m 2014, em função de uma série de limitações impostas pela legislação eleitoral, em termos de propaganda política, a publicidade externa foi muito usada pelos candidatos. Especialmente no caso dos candidatos a deputado federal e a deputado estadual, que ainda enfrentam outra limitação: o tempo de aparição no Horário Gratuito de Propaganda Eleitoral, em rádio e em televisão. Em função da grande quantidade de concorrentes aos cargos, o tempo disponível para cada candidato faz com que suas propagandas políticas sejam muito rápidas e muito esporádicas também.

Com isso, os candidatos acabaram investindo fortemente nos cavaletes de rua. Conforme a lei eleitoral, este tipo de publicidade externa móvel podia ser colocado ao longo das vias públicas, desde que não dificultassem o trânsito de pessoas e veículos e nem fossem instalados em árvores, postes ou placas de trânsito. A única obrigatoriedade prevista na legislação é que estes materiais deveriam ser colocados e retirados todos os dias, podendo ficar expostos das 06:00 às 22:00.

O problema é que as principais avenidas e cruzamentos das cidades foram tomadas e até mesmo infestadas por estes cavaletes, gerando uma enorme poluição visual. A partir desta questão é que surge o nosso problema de pesquisa: este acúmulo de quase um cavalete sobre o outro cria uma sensação de atração ou de distração em relação às propagandas políticas dos candidatos? Afinal, a publicidade externa é um dos elementos da paisagem urbana, assim como as placas de trânsito, que precisam ser visualizadas para orientar os motoristas e pedestres e, assim, evitar acidentes nas ruas e avenidas. 
A pesquisa utiliza, como suporte metodológico, a perspectiva funcionalista, que permite analisar as relações entre os meios de comunicação e a sociedade. E, para entender melhor estes processos e relações, foi aplicado um estudo de recepção para medir e avaliar se há um processamento da linguagem e uma consequente sensação de atração ou de distração em relação aos cavaletes de rua colocados pelos candidatos.

Como corpus inicial de pesquisa, foram selecionadas três figuras que retratam paisagens urbanas, nas quais é possível identificar a presença de cavaletes de propaganda política. Porém, este não foi o único critério de escolha do corpus. Buscou-se, também, imagens em que, além das publicidades, houvesse placas de sinalização de trânsito. A partir do corpus, determinamos que a pesquisa de recepção fosse aplicada junto a pessoas que dirigem. Por isso, estabeleceu-se que a pergunta filtro seria: "Você dirige?".

No sentido de conferir um resultado mais confiável à investigação, decidiu-se ainda que os respondentes deveriam ter formação superior concluída ou em andamento. O objetivo deste critério complementar é a suposição de que indivíduos com formação superior, em função de seus estudos e do acesso à informação, possuem maior letramento político. Para cada figura analisada foram escolhidas 12 pessoas, sendo seis homens e seis mulheres. No total, portanto, foram entrevistadas 36 pessoas. Cada um deles, após a mensagem "Repare na imagem a seguir", respondeu à seguinte pergunta: "O que mais lhe chamou a atenção na imagem?". Apenas reforçando que as pessoas visualizavam e respondiam a pergunta para a figura apresentada. Elas não viam as demais figuras.

O tempo de exposição de cada figura para os entrevistados foi de três segundos. O critério de escolha para esse tempo de exposição foi embasado nas teorias da publicidade e propaganda em relação ao tempo médio de visualização de um outdoor, que varia entre três e cinco segundos. Optou-se pelo menor tempo, pois como foram selecionadas pessoas que dirigem, a atenção para o trânsito diminui ainda mais o tempo e a capacidade de leitura de uma publicidade externa.

\section{Publicidade: um dos signos da paisagem urbana}

Para Mendes (2006: 35), “(...) a paisagem urbana pode ser definida como a percepção individual, espacial e temporal da composição de todos os seus elementos fixos (edificações, árvores, pavimentação, ruas), semifixos (anúncios, comércio ambulante) e móveis (automóveis, pessoas)".

Ou seja, como a cidade busca ao máximo a sua funcionalidade, a publicidade, como um elemento importante da paisagem, apresenta-se como solução, mas também como um problema. De acordo com Lynch (1997), os elementos que compõem a estrutura urbana também podem ser associados para valorizar determinadas características da própria paisagem ou torná-las imperceptíveis. Uma estátua 
pode tornar a praça onde está situada um núcleo de identificação do bairro e de sua comunidade. $\mathrm{Ou}$, ao contrário, contribuir para a formação de um ruído visual desintegrador, que impede a percepção de unidade da imagem daquele bairro.

Por isso é que, ainda com base em Lynch (1997: 80):

(...) a mídia exterior poderia ser considerada mais um elemento físico da paisagem urbana, com capacidade para desempenhar, como os demais elementos, determinadas funções ou colaborar para a definição da maioria das funções dos elementos citados - de limite, bairro, ponto nodal e marco - conforme os locais em que estiver instalada e sua utilização pelos cidadãos.

À publicidade, a cidade oferece os seus espaços. Afinal, como definem Drigo e Souza (2008), a cidade não pode abandonar a publicidade, pois isso corresponderia a abandonar os seus usuários. Como prosseguem as autoras, sem a publicidade os objetos não seriam o que são; ou seja, ela traz calor, constrói uma ambiência que favorece a absorção espontânea dos valores sociais ambientais e a regressão individual no consenso social. A publicidade movimenta a vida. Na mesma linha de raciocínio, Baudrillard (2004: 183) complementa:

Caso se suprimisse toda a publicidade, cada qual iria se sentir frustrado diante de muros despidos. Não apenas por deixar de ter uma possibilidade (mesmo irônica) de jogo e de sonho, porém mais profundamente pensaria que não se preocupam mais com ele. Ele sentiria saudade deste meio ambiente onde, por falta de participação social ativa, poderia participar, ao menos em efígie, do corpo social, de uma ambiência mais calorosa, mas maternal, mais colorida. Uma das primeiras reivindicações do homem no seu acesso ao bem-estar é a de que alguém se preocupe com seus desejos, com formulá-los e imaginá-los diante de seus próprios olhos (...). A publicidade desempenha esta função fútil, regressiva, inessencial, mas com isso, tanto mais profundamente exigida.

Segundo Sanchéz (2001: 16), “o espaço é ocupado ao máximo por propagandas que tentam criar convenções urbanas, redefinindo a cotidianeidade humana e seu nível de apropriação do espaço". Em função disso, a publicidade externa não apenas ocupa o seu papel de elemento na paisagem urbana, como também acaba tendo um papel importante nos processos que acompanham a renovação urbana. Segundo Moles (1974), entre os diversos segmentos da sociedade que passaram a se valer da publicidade externa está a política, para veicular suas mensagens e se dirigir aos cidadãos.

A questão que se coloca é se essa estratégia, de quase um cavalete sobre o outro, gerou uma sensação de atração ou de distração em relação às propagandas políticas dos candidatos. Afinal, segundo Mendes (2006: 19): 
(...) a comunicação humana, contida entre a recepção e a compreensão das mensagens, realiza-se por meio de um processo cognitivo complexo, constituído de três fases: percepção (relacionada ao campo sensorial), seleção (campo da memória) e atribuição de significados (campo do raciocínio). Esse processo leva a dois fins precisos: ação e memorização.

Ainda de acordo com a autora, do ponto de vista sensório-perceptivo, o ser humano é um animal predominantemente óptico. Utiliza o sentido da visão mais do que qualquer outro para interagir com o mundo. Isso pode ser comprovado pela neurologia, ao constatar que cerca de dois terços das funções cerebrais relacionam-se à visão e cerca de $85 \%$ da percepção humana decorre desse sentido, que pode ser exposto, em um único dia, a mais de 23 mil informações visuais (Mendes, 2006).

De acordo com Gazzaniga (2006), dentre as modalidades sensoriais, a visão se torna especialmente importante, pois ela permite que a informação seja percebida a distância, não necessitando de um contato imediato com o objeto, como os demais sentidos. Estudos demonstram que a performance do sistema visual humano é impressionante. Conforme Thorpe (1988), estima-se que as pessoas conseguem reconhecer cerca de cem mil objetos entre cem e duzentos ms (ms é uma medida conhecida como milissegundos). Neste processo de visualização, a retina consiste no primeiro estágio da hierarquia de atenção visual. A alta resolução da fóvea (a fóvea é a região central da retina do olho humano onde se concentram os cones nos quais se forma a imagem que será transmitida ao cérebro) permite identificar precisamente a região central da imagem ao mesmo tempo em que mantém uma representação vaga da periferia do objeto.

Segundo Pieters e Warlop (1999), o rastreamento visual ocorre por fixação ou por intermédio de pulos (eye-saccades). Os pulos são movimentos mais rápidos, quando os olhos de uma pessoa vão de um campo visual a outro; enquanto as fixações são as pausas que os olhos fazem entre cada pulo. De acordo com Petroll (2013), o pulo pode durar de 10 milissegundos à cerca de cem milissegundos, conforme Duchowski (2007). Já as fixações variam entre 150 milissegundos a 600 milissegundos, dependendo das características do estímulo (Duchowski, 2007).

Em termos de rastreamento ocular e de atração visual, de acordo com Neves, Gonzaga e Frère Slaets (s/d), a percepção de objetos que podem ser reconhecidos em diferentes pontos de vista, em diferentes tamanhos e em diferentes posições no espaço é conseguida, também, através da separação da informação proveniente da retina em dois caminhos visuais. Pesquisas mostram que o caminho que atinge a área parietal é crucial para localizar objetos ("onde”), ao passo que a informação que atinge a área temporal é crucial para o reconhecimento da forma ("o que"). Como há essa separação da informação, também há a necessidade de combinar essas informações a fim de se identificar e localizar o objeto ao mesmo tempo. Por isso, 
após ser processada na retina, a informação visual é direcionada para duas diferentes áreas do cérebro.

Ainda segundo Neves, Gonzaga e Frère Slaets (s/d), um objeto pode atrair a atenção de duas maneiras: primeiro, de forma exógena e, segundo, de característica endógena. Para entender melhor a diferença entre as duas, quando se trata de objetos que diferem muito de seu ambiente, como, por exemplo, em relação à cor, tamanho, continuidade ou orientação tridimensional; ou, ainda, objetos que são de relevância especial, como o nome de alguém, ocorre a atenção exógena ou também chamada de bottom-up.

Neste primeiro estágio, chamado de pré-atentivo, características consideradas simples dos objetos são extraídas em paralelo, realizando-se, assim, um processo de segmentação, de agrupamento perceptual e de levantamento das regiões relevantes que serão interpretadas posteriormente. O primeiro estágio pode ocorrer, inclusive, de forma despretensiosa, pois o sistema visual humano possui a característica de não necessitar de atenção consciente. Torna-se importante recordar das qualidades da forma, definidas e apresentadas anteriormente por Lynch (1997), cujo objetivo é, justamente, contribuir para a percepção e a atração visual.

Já na atenção endógena ou denominada de top-down, os níveis cognitivos mais altos no cérebro influenciam o sistema atencional no sentido de selecionar uma característica particular do objeto ou uma combinação de características. O segundo estágio, denominado atentivo ou focal, utiliza as informações de baixo nível do estágio anterior e, também, informações de alto nível, como conhecimento prévio e do contexto, para focalizar o processamento em localizações particulares do campo visual e, com isso, reconhecer e determinar as possíveis relações entre os objetos.

Em parte, sobretudo para uma publicidade externa estática e fixada na paisagem urbana, tanto do ponto de vista exógeno ou endógeno, o objetivo da atração estaria resolvido. Porém, o problema crítico do sistema de atenção é justamente a necessidade de engajamento atencional continuado contra a necessidade de sua interrupção. Especialmente no contexto urbano repleto de elementos fixos, semifixos e móveis, como define Mendes (2006), seria muito natural que o processo de atração sofresse e, de fato, sofra interferências significativas desencadeadas pelo ambiente.

No sentido de tentar responder a esse problema crítico do sistema de atenção, Manteigueiro (2011: 24) afirma que "o processamento da informação está dividido em quatro níveis, sendo estes a percepção, a atenção, a memória e o raciocínio". Em termos de percepção, em especial no campo da publicidade, Batista, Rodrigues, Brizante e Francheschi (2008: 138) definem que,

(...) os processos de influência na relação da propaganda com o indivíduo podem ser considerados a partir do seu conteúdo explícito, ou seja, as informações, os personagens, o formato de apresentação, entre outros (...) No 
entanto, esta influência pode ocorrer também pela inserção de material publicitário de maneira não obstrutiva, ou seja, pela colocação de propagandas no campo de visão do indivíduo, onde estas não constituem o centro da atenção e, desta maneira, enquanto o interesse por outra atividade prende a atenção do receptor, a informação da propaganda é captada de forma não intencional.

Em termos de atração, conforme Manteigueiro (2011), há cerca de 50 anos, os psicólogos definiam atenção como uma focalização da consciência ou um aumento de clareza de uma ideia particular. Ao longo do tempo, os estudos, as teorias e as experiências também evoluíram. Uma das mais importantes foi a contribuição de Broadbent (1958), que desenvolveu a teoria do filtro da atenção, tornando-se imprescindível para a compreensão do fenômeno da atenção seletiva.

Ou seja, o autor elaborou um modelo em que diversas mensagens, através de diferentes canais receptivos, podem chegar até um sistema seletivo denominado de filtro. Este filtro bloqueia algumas mensagens e coloca outras para um canal de decisão de capacidade limitada. Este canal tem acesso à memória de longo prazo, que determina a resposta apropriada. A grande inovação neste modelo de atenção seletiva é que o indivíduo pode receber mais do que um estímulo ao mesmo tempo e selecionar a qual responder.

Seguindo o pensamento de Manteigueiro (2011), de que o processamento da informação está dividido em quatro níveis, depois da percepção e da atenção, temos a questão da memória. De acordo com Gleitman, Fridlind e Reisberg (2003), a memória é a maneira como fazemos o registro dos acontecimentos das nossas vidas, das informações e competências que advêm desses acontecimentos. Para um efetivo armazenamento da informação, Manteigueiro (2011) afirma que a ativação da memória ocorre em quatro etapas. No nível da aquisição da informação é onde se realiza o primeiro contato com o estímulo que o indivíduo pretende armazenar ou para o qual teve a sua atenção atraída. Para a autora, nesta fase torna-se importante, também, o grau de atenção do sujeito, pois isso implicará em uma correta aquisição da informação ou eventuais erros ou dissonâncias cognitivas de interpretação.

A etapa seguinte diz respeito à codificação do objeto ou da mensagem percebida. Neste caso, de alguma forma, o indivíduo tentará atribuir significado àquela informação apreendida. O significado que for atribuído será muito importante para o próximo passo da memória, que é o armazenamento. A fase de armazenamento tem relação com o traço mnésico; ou seja, com a marca a ser deixada por uma informação no sistema nervoso central. Esse traço mnésico poderá ser permanente ou temporário.

A última etapa é chamada de recuperação e ocorre quando as pessoas tentam se lembrar de alguma informação armazenada em sua memória, tendo acesso, portanto, a um traço mnésico. Justamente este processo todo de memória e armazenamento da 
informação é que fará com que os indivíduos sintam-se atraídos para determinado objeto ou mensagem ou verifique-se um fenômeno de desatenção, de abstração e de ausência da informação.

\section{Atração ou distração?}

A seguir, então, será feita a análise de cada uma das imagens estudadas. A pesquisa foi realizada na cidade de Porto Alegre, do dia 06/05/2015. Mesmo que as figuras não fossem especificamente de Porto Alegre, este fato não gerou nenhum comentário e nenhum estranhamento por parte dos entrevistados. Não se tratando, portanto, nenhum limitador da pesquisa.

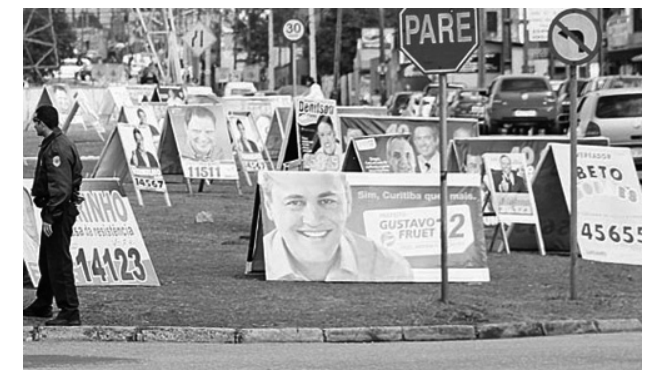

Figura 1: Cavaletes de propaganda política - primeira imagem Fonte: Google Imagens

Na primeira imagem analisada, encontramos uma placa de sinalização indicando "Pare", uma segunda placa informando que não é possível dobrar à esquerda; aparentemente um guarda (não fica claro se é um guarda de trânsito ou não); duas outras placas mais ao fundo; um grande fluxo de movimentos de carros ao lado direito da figura; e uma quantidade enorme de cavaletes de propaganda eleitoral, com destaque para o candidato Fruet mais à frente e outra publicidade ao lado em que não se pode identificar o candidato, mas visualiza-se o número deste candidato.

Das seis entrevistadas do público feminino, apenas três identificaram a placa de Pare. Ou seja, a poluição visual causada pode ser um grave risco de acidentes para os motoristas. Somente uma delas viu a presença do guarda. Entretanto, todas perceberam a existência dos cavaletes. Ainda assim, nenhuma das mulheres teve a sensação de atração para as publicidades dos candidatos, pois ninguém lembrou o nome de alguns dos candidatos. Curiosamente, três destas entrevistadas, em suas respostas, disseram a mesma coisa: "um monte de propaganda política".

Entre o público masculino, da mesma forma que as mulheres, apenas três identificaram a placa de "Pare". O termo poluição foi mais enfatizado pelos homens. 
Quatro dos entrevistados utilizaram o termo como primeiro item de suas falas. Um deles, inclusive, chegou a dizer: "incrível poluição". Já diferente do público feminino, em duas oportunidades o nome Fruet foi citado pelos homens e em outras duas vezes foi mencionado "o rosto de um cara". Embora o caráter quantitativo não seja o objeto de nossa pesquisa, das 12 pessoas entrevistadas, apenas duas delas conseguiram perceber o nome de um dos candidatos divulgados nos cavaletes. Com isso, pode-se afirmar que a imagem analisada não proporcionou a sensação de atração.

Fica evidente, pelos princípios da Gestalt, que a enorme quantidade de elementos e a disposição destes elementos, não permite o agrupamento das informações, pois no caso os objetos estão muito próximos uns dos outros, não há unidade entre os cavaletes e a paisagem urbana, nem similaridade e nem continuidade, afetando, com isso, a compreensão, a percepção e a fluidez visual.

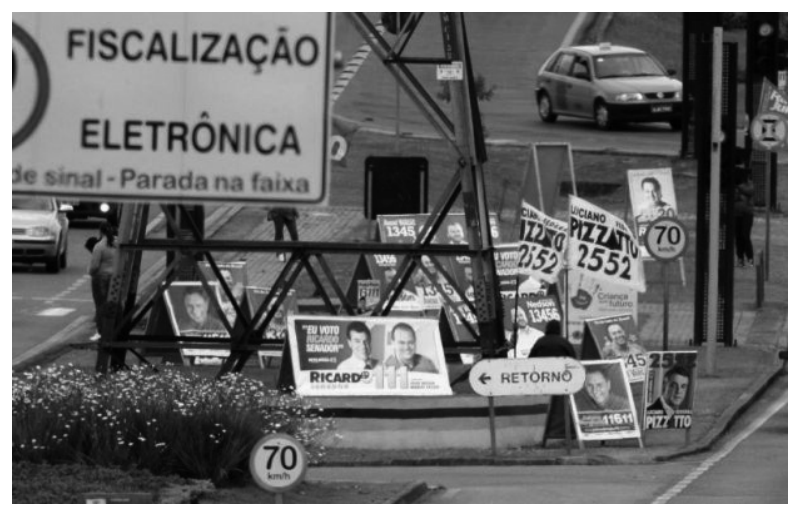

Figura 2: Cavaletes de propaganda política - segunda imagem Fonte: Google Imagens

Já na segunda imagem analisada, podemos ver a estrutura de um poste (provavelmente de cabos de energia); diversos cavaletes em torno desta estrutura; uma placa de limite de velocidade indicando 70 quilômetros por hora em primeiro plano; duas outras placas mais à direita da imagem; uma pequena placa de retorno à frente dos cavaletes; uma grande placa de fiscalização eletrônica no canto esquerdo da figura; e um táxi fazendo o retorno ao fundo.

Entre o público feminino, desta vez não houve unidade entre as respostas. Somente duas das entrevistadas mencionaram a placa de sinalização eletrônica. Outras três disseram que havia uma placa, mas não souberam informar o que estava escrito nela. E uma delas chegou a dizer que estava escrito Pare. A partir de uma visão mais sistêmica da imagem, duas mulheres perceberam a presença do táxi mais à frente. Todas identificaram os cavaletes de propaganda eleitoral. Porém, sem conseguir dizer nome, número do candidato ou mesmo alguma cor que pudesse 
lembrar o partido político. A questão da cor foi provocada no momento da entrevista, porque há um predomínio das cores azul, verde e vermelho nas publicidades. Entretanto, nem isso chamou a atenção.

Com relação ao público masculino, assim como ocorreu entre as mulheres, houve uma grande sensação de distração. Até maior entre os homens. Somente dois identificaram a placa de sinalização eletrônica. Outro percebeu a placa indicativa da velocidade máxima de 70 quilômetros por hora. E outro, ainda, viu que havia uma placa, mas não soube dizer o que estava escrito. O mais curioso, entretanto, foi quanto aos cavaletes. Quatro entrevistados perceberam a existência das propagandas eleitorais. Porém, em dois dos homens pesquisados, para um o que chamou a atenção foi a presença de lixo reciclável na imagem. Já o outro afirmou que havia caixas.

Assim como a imagem anterior, novamente pode afirmar que a compreensão, a percepção e a fluidez visual ficam prejudicadas. Não houve sequer um agrupamento das informações, pois neste caso a sensação de distração foi muito grande. Inclusive com a (falsa) percepção de elementos que nem mesmo estão presentes na imagem. Desta vez, nenhuma das 12 pessoas entrevistadas citou o nome de um candidato.

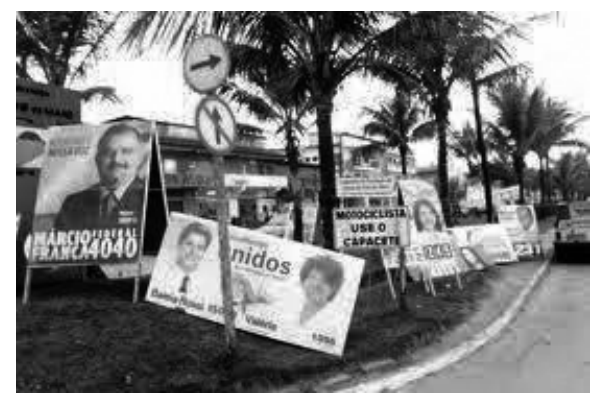

Figura 3: Cavaletes de propaganda política - terceira imagem Fonte: Google Imagens

Por fim, na terceira imagem analisada, vemos algumas árvores na calçada; um poste com duas placas de trânsito em primeiro plano, uma delas indicando o sentido obrigatório e a outra proibindo seguir em frente; e alguns cavaletes de propaganda eleitoral. Embora não exista uma calçada definida, parte dos cavaletes está obstruindo a passagem no passeio público (o que contraria a legislação eleitoral).

Nesta imagem, pode-se dizer que o público feminino entrevistado sentiu-se mais atraído para as mensagens visuais. Entretanto, acabou sendo uma percepção errada, pois uma das mulheres mencionou que estava escrito Lula em uma das propagandas. Outra, afirmou que era a figura de Dilma (na verdade, ainda que o nome da candidata esteja pequeno, é Valéria). E, uma terceira, leu Marco; quando, na verdade, o nome correto do candidato é Márcio. As que não identificaram nenhum nome de candidato, curiosamente, citaram a expressão "aparentemente, 
cartazes de propaganda política”. Em relação à sinalização de trânsito, quatro mulheres perceberam as placas indicativas de direção obrigatória e de proibido seguir em frente.

Entre os homens, a percepção dos entrevistados em relação à imagem acabou sendo muito parecida. Todos mencionaram a presença de cartazes de propaganda política. Não conseguem identificar nenhum dos candidatos. E, para três dos pesquisados, é possível identificar a presença das placas indicativas de sentido obrigatório e de sentido proibido. Em nossa opinião, essa quase unanimidade de opiniões entre o público masculino justifica-se porque a visão da imagem não possui profundidade de campo e o olhar do motorista divide-se entre os objetos colocados e a necessidade de ater-se ao trânsito.

De qualquer forma, mantêm-se os resultados verificados nas imagens anteriores. Isto é, um prejuízo quanto à compreensão, à percepção e à fluidez visual. Neste cenário, aparentemente, os elementos visuais parecem mais agrupados. Mas, da mesma maneira que os casos analisados anteriormente, a sensação de distração permanece. Entretanto, diferente das outras duas figuras, a distração aqui aparece em aspectos distintos. Primeiro, porque os cavaletes estão muito próximos da rua ou avenida. Isso faz com que se crie quase um bloco único de informações. Percebe-se o todo, mas não as partes. Segundo, porque a distração, neste caso, acaba tendo um significado de perturbação. Ou seja, os cavaletes prejudicam a visualização do trânsito e das placas de sinalização. O motorista não tem uma visão espacial ampla sobre o canteiro e do movimento de carros e pedestres do outro lado da rua.

\section{Considerações finais}

No Reino Unido, diversos estudos sobre atração e distração visual têm sido realizados para medir e avaliar se a atenção visual dos motoristas é atraída para os anúncios colocados à beira das estradas. Em uma pesquisa realizada em 2005, pelo Fundo de Estradas Jeffrey Rees, mais de um quarto dos motoristas admitiu perder a concentração devido a anúncios de beira de estrada. Para $41 \%$ dos entrevistados, essa distração chegou a ser de até cinco segundos. Em termos de distração, entre as diversas conclusões obtidas nos estudos dos autores, os motoristas mostraram-se mais atraídos para as publicidades do que para os sinais de trânsito mais relevantes.

No Brasil, estudos desta natureza ainda são escassos. Por aqui, os conceitos de atração e distração visual ainda estão distantes das pesquisas relacionadas à publicidade externa. Em geral, as pesquisas nesta área limitam-se à aplicação das técnicas publicitárias, de design ou, ainda, quanto à poluição visual produzida por esta mídia no contexto urbano.

Para se chegar à conclusão de que a grande quantidade de cavaletes de propaganda política cria uma sensação de poluição visual, nem sequer seria necessário fazer 
qualquer levantamento. Porém, nosso objetivo era o de ir mais além. No caso, ao inserir as pessoas na condição de motoristas naqueles cenários apresentados nas três imagens, nossa pretensão era a de verificar quais elementos visuais seriam capazes de serem percebidos e memorizados. Com isso, descobrir, então, se havia ou não uma consequente sensação de atração. Ou, ainda, como também se verificou, de que os cavaletes políticos acabaram gerando um fenômeno de distração em relação às placas de trânsito.

Mesmo sem a utilização de grandes recursos tecnológicos de aferição do movimento ocular dos indivíduos entrevistados, em função dos elementos visuais que chamaram mais a atenção pela sua disposição nas imagens pesquisadas, foi possível perceber que o campo de visão das pessoas alternava basicamente em duas direções:

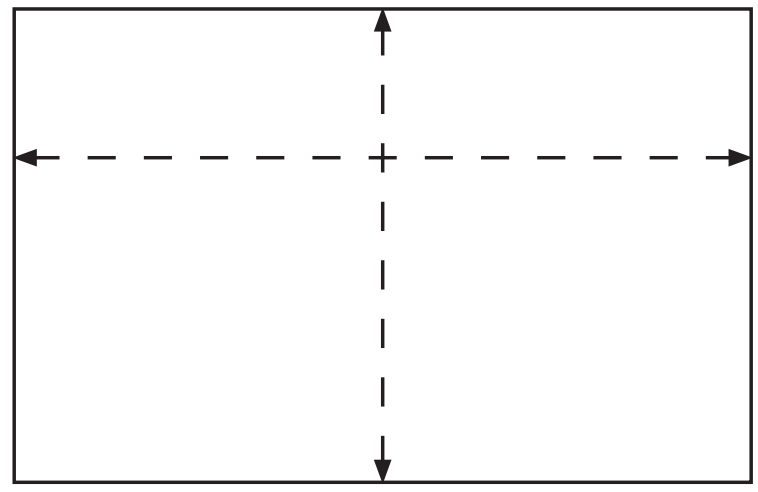

Figura 4: Sentidos de leitura

Fonte: Autor

Ou seja, embora a pesquisa não tenha um caráter quantitativo, a atração visual dos entrevistados foi bem maior nestas duas áreas. Tornou-se uma informação adicional à pesquisa. Os indivíduos agrupam os objetos próximos uns dos outros, formam as unidades e organizam a sua percepção com alguma coerência, evitando, assim, interrupções na sua trajetória ou na sua fluidez visual. Essa informação seria fundamental aos candidatos políticos e às suas assessorias de comunicação, pois não basta simplesmente colocar os cavaletes de propaganda política, concorrendo não apenas com os demais candidatos. É preciso levar em consideração a paisagem urbana, os elementos visuais ali presentes, os campos de visualização e de possíveis movimentos oculares das pessoas e a própria sinalização de trânsito.

Por fim, do ponto de vista político, este fenômeno da atração e da distração acaba revelando até mesmo uma contradição de postura por parte dos candidatos. Afinal, boa parte destes candidatos, em suas campanhas, discursos e propostas eleitorais, defende a ideia de trabalhar pela segurança das pessoas no trânsito. Entretanto, seus 
próprios cavaletes políticos e eleitorais contribuem para o aumento da insegurança, através do efeito de distração, como se verificou nesta pesquisa.

Sérgio Roberto Trein

Pós-doutorando na Universidade de São Paulo (USP).

sergiotrein@uol.com.br

Recebido em julho de 2015.

Aceito em outubro de 2015.

\section{Referências}

BATISTA, Leandro Leonardo; RODRIGUES, Carla Daniela Rabelo; BRIZANTE, Janaína Geraldes e FRANCHESCHI, Reginaldo. Aspectos cognitivos da percepção na propaganda. Rio de Janeiro: Revista Ciências \& Cognição, v. 13 (3), p. 137-150, 2008.

BAUDRILLARD, J. O sistema dos objetos. São Paulo: Perspectiva, 2004.

BROADBENT, D. Perception and communication. Londres: Pergamon, 1958.

DRIGO, Maria Ogécia e SOUZA, Luciana Coutinho Pagliarini de. Paisagem urbana como sistema de comunicação: um olhar para a cidade de São Paulo. São Paulo: Revista Pós, n. 28, jun., 2008.

DUCHOWSKI, A. Eye Tracking Methodology: Theory and Practice. New York: Springer, 2007. GAZZANIGA, M. S. e HAETHERTON, T. F. Ciência psicológica: mente, cérebro e pensamento. Porto Alegre: Artmed, 2005.

GLEITMAN, Henry; FRIDLUND, Alan J. e REISBERG, Daniel. Psicologia. Lisboa: Fundação Calouste Gulbenkian, 2003.

LYNCH, K. A imagem da cidade. São Paulo: Martins Fontes, 1997.

MANTEIGUEIRO, Ana Catarina Nicolau. A publicidade clandestina no audiovisual: um estudo de eye tracking. Aveiro: Universidade de Aveiro, 2011.

MENDES, Camila Faccioni. Paisagem urbana: uma mídia redescoberta. São Paulo: Editora Senac São Paulo, 2006.

MOLES, Abraham Antoine. O cartaz. São Paulo: Perspectiva, 1974.

NEVES, Evelina Maria de Almeida; GONZAGA, Adilson e FRÈRE SLAETS, Annie France. Atenção visual seletiva para reconhecimento de objetos e análise de cenas. São Carlos, Multiciência, v. 4, p. 26-44, s/d.

PETROLL, Martin de la Martinière. Os pop-up ads estão entre nós: a invasão desse placement televisivo e seus efeitos sobre o consumidor com auxílio da tecnologia do eye-tracking. Curitiba: Universidade Federal do Paraná, 2013.

PIETERS, R. e WARLOP, L. Visual attention during brand choice: the impact of time pressure and task motivation. International Journal of Research in Marketing, v. 16, n. 1, p. 1-16, 1999. SANCHÉS, Fernanda. A reinvenção das cidades na virada de século: agentes, entratégias e escalas de ação política. Curitiba: Rev. Sociol. Política, 2001.

THORPE, S.J. Traitment dímages chez l'homme. Technique et Science Informatiques, v. 7, n. 6, p.517-525, 1988. 


\title{
Resumo
}

Em 2014, em função de uma série de limitações impostas pela legislação eleitoral, a publicidade externa foi muito usada pelos candidatos. O problema é que as principais avenidas e cruzamentos das cidades foram tomadas por cavaletes, gerando uma enorme poluição visual. A partir desta questão é que surge o nosso problema de pesquisa: este acúmulo de quase um cavalete sobre o outro cria uma sensação de atração ou de distração em relação às propagandas políticas dos candidatos? Para isso, como suporte metodológico, será utilizada a perspectiva funcionalista, que permite analisar as relações entre os meios de comunicação e a sociedade. E, para entender melhor estes processos e relações, será aplicado um estudo de recepção para medir e avaliar se há um processamento da linguagem e uma consequente sensação de atração ou de distração em relação aos cavaletes de rua colocados pelos candidatos.

\section{Palavras-chave}

Atração. Distração. Publicidade externa.

\begin{abstract}
In 2004, because of a series of limitations imposed by electoral legislation, external publicity was much used by candidates. The problem is that the main city avenues and street intersections were dominated by political sidewalk signs, producing a significant amount of visual pollution. It is from this situation that our research problem has come up: does this accumulation of sidewalk signs create a sensation of attraction or distraction in relation to these candidates' political propaganda? For this purpose, the functionalist approach will be used as methodological support, since it allows the analysis of the relation between the means of communication and society. To better understand these processes and relations, a reception study will be used to measure and evaluate the existence of a language processing and its consequent sensation of attraction or distraction in relation to the sidewalk signs on streets put there by candidates.
\end{abstract}

\section{Keywords}

Attraction. Distraction. External advertising. 